\title{
Medical treatment of staphylococcal infective endocarditis
}

\author{
J. BILLE
}

University Hospital (CHUV), Lausanne, Switzerland

KEY WORDS: Staphylococci, endocarditis, antibiotherapy.

Staphylococcal infective endocarditis is a severe event requiring aggressive therapy. Antibiotic regimen depends mainly on (1) the species of Staphylococcus (Staphylococcus aureus versus coagulase-negative staphylococci) and its resistance pattern (resistance to penicillin, to methicillin, to multiple classes of antibiotics); (2) the type of infected valve (native versus prosthetic); (3) the site of infection (left side versus right side endocarditis); (4) some underlying conditions of the host, in particular the presence or not of intravenous drug abuse. Based on in vitro susceptibility results, animal models and clinical trials, the following regimens are currently recommended. For native valve endocarditis, penicillin $G 20$ million units per day i.v. for $4-6$ weeks for penicillin-susceptible strains; a penicillinase-resistant penicillin (oxacillin) $2 \mathrm{~g}$ i.v. $q 4 \mathrm{~h}$ for $4-6$ weeks plus an aminoglycoside (gentamicin) $1.0 \mathrm{mg} \cdot \mathrm{kg}^{-1}$ iv. $q 8 \mathrm{~h}$ for 1 week, for penicillin-resistant, methicillin-susceptible strains;

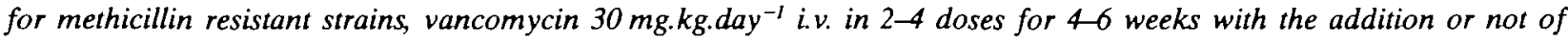
rifampin $600-900 \mathrm{mg}^{-d a y^{-1}}$ orally. For a prosthetic valve endocarditis, a three-drug regimen (oxacillin or vancomycin, plus gentamicin and rifampin) and a longer duration (6 weeks or more) are generally recommended. Shorter (2 weeks) treatment could be delivered to uncomplicated cases of right-sided endocarditis In view of an increased resistance to classic drugs and suboptimal efficacy of some of them, new therapeutic modalities should be looked at, in particular for endocarditis cases due to methicillin-resistant strains

\section{Introduction}

Among the causative agents of infective endocarditis, staphylococci play an important and varied role. Quantitatively, they rank second only to streptococci in many series. Their presentation, clinical course, therapeutic requirements and prognosis vary widely in relation to the type of Staphylococcus, the site and type of the valve infected and other host factors. On the whole, staphylococcal infective endocarditis is a severe disease requiring a precise diagnosis and an aggressive therapeutic approach. Despite this, mortality remains substantial in some categories and an associated surgical treatment is quite often required.

\section{The bacteria}

Staphylococci are divided into two main groups: coagulase-positive staphylococci called Staphylococcus aureus, and coagulase-negative staphylococci (CNS), comprising more than 15 species found in man, with $S$. epidermidis being the predominant one.

Regarding their sensitivity to antibiotics, the staphylococci can be divided into three categories:

(i) staphylococci susceptible to all $\beta$-lactam agents, also called penicillin-susceptible or $\beta$-lactamase-negative staphylococci. They are a minority today and represent $5-20 \%$ of all $S$. aureus and of all coagulase-negative staphylococci.

(ii) staphylococci resistant to penicillin (and to the aminopenicillins and ureidopenicillins), but susceptible to

Correspondence Prof. J. Bille, Clinical Bacteriology Laboratory, CHUV. B H19S, CH-1011 Lausanne, Switzerland. methicillin (and to various degrees to cephalosporins). These staphylococci are called $\beta$-lactamase-positive staphylococci. They represent the majority of the staphylococci in many countries and institutions, in particular, where the number of methicillin-resistant strains is low.

(iii) staphylococci resistant to penicillin ( $\beta$-lactamase positive) and to methicillin due to the presence of an altered penicillin-binding protein (called PBP 2a) in the cell wall, with a low affinity for the $\beta$-lactam antibiotics. Though they often appear susceptible in vitro to various $\beta$-lactam agents, these methicillin-resistant (MR) staphylococci are considered universally resistant to all $\beta$-lactam antibiotics.

It should be cautioned that the in vitro demonstration of methicillin resistance is sometimes difficult, particularly for $S$. epidermidis and other CNS, and that most of the rapid automated instruments for antibiotic susceptibility testing often fail to detect this resistance.

The incidence of methicillin resistance in staphylococcal strains varies widely from institution to institution (from $1-2 \%$ to more than $50 \%$ ) and local data will condition the initial empiric antibiotic regimen for staphylococcal infections.

Methicillin-resistant staphylococci are usually also resistant to other families of antibiotics such as the aminoglycosides, the macrolides and the quinolones. Antibiotic regimens other than vancomycin should, therefore, only be based on in vitro susceptibility testing.

Vancomycin constitutes a unique exception, in that no clinical $S$. aureus strain resistant to this glycopeptide has so far been described. However, resistance to vancomycin is to be expected in the future, because the transfer of such resistance has occurred in vitro between enterococci and staphylococci. 


\section{The host}

With staphylococcal endocarditis, perhaps more so than with any other aetiology, two important and related host factors exist: the site(s) of the infected valve(s) and the type of patient (whether intravenous drug abuser (IVDA) or not).

Usually, IVDAs present a right-sided $S$ aureus endocarditis, which is a less severe disease, allowing a shorter therapeutic regimen, at least for as long as there are no lesions on the left side and no complications such as metastatic emboli.

Non-IVDA patients most often present left-sided $S$. aureus endocarditis and require a full course (4-6 weeks) of parenteral administration of a combination of two or more bactericidal drugs to which the isolate is susceptible.

Another very important factor lies in the type of the valve involved, i.e. native versus prosthetic valve. Infection of prosthetic material is probably more difficult to cure and three antibiotics are often recommended in this situation.

\section{Recommended antibiotic regimens}

Recommended treatment regimens for staphylococcal endocarditis are based on in vitro data, on results obtained in animal models and occasionally on deductions from prospective randomized comparative trials in $\operatorname{man}^{[1-2]}$. They vary from country to country according to antibiotic policies and drug availability or preference. It is beyond the scope of this article to review all the data leading to recommendations of antibiotherapy. Current regimens will be given for each particular situation and emphasis will be put on the related problems or possible new treatment modalities and developments.

\section{NATIVE VALVE (TABLE 1)}

\section{Left-sided $S$. aureus endocarditis}

Infections due to a penicillin-susceptible strain (a rare event) can be treated with penicillin G 16-20 million units per day i.v. in four to six divided doses for $4-6$ weeks. There are no clinical studies comparing this regimen to alternative regimens.

Infections due to a penicillin-resistant but methicillinsusceptible strain (representing the majority of cases in many institutions) requires the parenteral administration of a penicillinase-resistant semi-synthetic penicillin such as oxacillin, flucloxacillin (Europe) or nafcillin (U.S.A.) associated or not with an aminoglycoside (generally gentamicin or tobramycin).

The usual dosage for the $\beta$-lactam is $2 \mathrm{~g} \mathrm{q} 4 \mathrm{~h}$ i.v. for $4-6$ weeks. The dosage for the aminoglycoside (gentamicin or tobramycin) is $1.0 \mathrm{mg} \cdot \mathrm{kg}^{-1} \mathrm{q} 8 \mathrm{~h}$ i.v. for $3-5$ days.

The only prospective comparative study available showed that 2 weeks of gentamicin associated with nafcillin versus nafcillin alone decreased the duration of bacteraemia ( 2.8 versus 1.1 days), but increased the level of renal toxicity. No difference in mortality was observed ${ }^{[3]}$.

Infections caused by a methicillin-resistant strain are treated at the present time with vancomycin, associated with or without other agents such as rifampin and/or aminoglycosides, when they are active on the strain.

Vancomycin should be given i.v. at a dosage of $30 \mathrm{mg}$. kg. day ${ }^{-1}$ in two to four equally divided doses for 6 weeks and adjusted to the renal function. Optimal peak and trough serum levels should be $25-30 \mu \mathrm{g} \cdot \mathrm{ml}^{-1}$ and $10 \mu \mathrm{g} \cdot \mathrm{ml}^{-1}$, respectively (in the $\mathrm{q} 12 \mathrm{~h}$ regimen). The proposition to add rifampin ( $600-900 \mu \mathrm{g}_{\text {.day }}{ }^{-1}$ orally for 6 weeks) is based on its excellent intra- and extracellular bactericidal activity on staphylococci. However, resistance to rifampin can occur, even when combined to vancomycin. For this reason also, a third drug such as gentamicin (only when the organism is susceptible) could be added for the first 2 weeks (gentamicin $1.0 \mathrm{mg}^{-k^{-1}} \mathrm{q} 8 \mathrm{~h}$ per day i.v.). There are no prospective clinical trials to back these recommendations; they are based on in vitro data and the results of animal studies demonstrating an increased efficacy of a three-drug regimen ${ }^{[4]}$.

Table I Antibiotic regimens for staphylococcal native valve endocarditis

\begin{tabular}{|c|c|c|c|c|c|}
\hline & & First choice & & & Alternative \\
\hline \multicolumn{6}{|l|}{ Staphylococcus aureus } \\
\hline $\begin{array}{l}\text { Left side IE } \\
\text { Penicillin-susceptible } \\
\text { Methicillin-susceptible }\end{array}$ & $\begin{array}{l}\text { Penicillin G } \\
\text { Oxacillin } \\
+ \text { gentamicin }\end{array}$ & 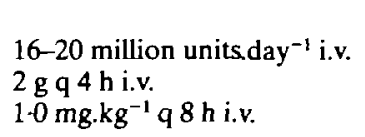 & $\begin{array}{l}\times 4-6 \text { weeks } \\
\times 4-6 \text { weeks } \\
\times 3-5 \text { days }\end{array}$ & & \\
\hline Methicillin-resistant & $\begin{array}{l}\text { Vancomycin } \\
+ \text { rifampin } \\
\pm \text { gentamicin }\end{array}$ & 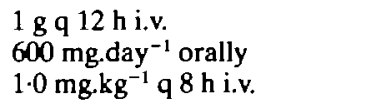 & $\begin{array}{l}\times 6 \text { weeks } \\
\times 6 \text { weeks } \\
\times 2 \text { weeks }\end{array}$ & & \\
\hline \multicolumn{6}{|l|}{ Right side IE } \\
\hline Methicillin-susceptible & $\begin{array}{l}\text { Oxacillin } \\
+ \\
\text { gentamicin }\end{array}$ & $\begin{array}{l}1.5 \mathrm{~g} \mathrm{q} 4 \mathrm{~h} \text { i.v. } \\
1.0 \mathrm{mg}^{\mathrm{kg}}{ }^{-1} \mathrm{q} 8 \mathrm{~h}\end{array}$ & $\begin{array}{l}\times 2 \text { weeks } \\
\times 2 \text { weeks }\end{array}$ & $\begin{array}{l}\text { Ciprofloxacin } \\
\text { then } \\
+ \\
\text { rifampin }\end{array}$ & $\begin{array}{l}300 \mathrm{mg} \mathrm{q} 12 \mathrm{~h} \text { i.v. for } 1 \text { week } \\
750 \mathrm{mg} \mathrm{q} 12 \text { h orally for } 3 \text { weeks } \\
300 \mathrm{mg} \mathrm{q} 12 \text { h orally for } 3 \text { weeks }\end{array}$ \\
\hline Methicillin-resistant & $\begin{array}{l}\text { Vancomycin } \\
+ \text { rifampin }\end{array}$ & $\begin{array}{l}1 \mathrm{~g} \mathrm{q} 12 \mathrm{~h} \mathrm{i.v.} \\
600 \mathrm{mg}^{\text {day }}{ }^{-1} \text { orally }\end{array}$ & $\begin{array}{l}\times 4 \text { weeks } \\
\times 4 \text { weeks }\end{array}$ & & \\
\hline $\begin{array}{l}\text { Coagulase negative stap } \\
\text { Methicillin-susceptible } \\
\text { Methicillin-resistant }\end{array}$ & $\begin{array}{l}\text { lococci } \\
\text { As for } S \text { aureus } \\
\text { As for } S \text { aureus }\end{array}$ & & & & \\
\hline
\end{tabular}


Right sided S. aureus endocarditis

Infections due to a methicillin-susceptible strain can be treated by a 2-week course of a semi-synthetic penicillinase-resistant penicillin (PRP) such as nafcillin $1.5 \mathrm{~g} \mathrm{q} 4 \mathrm{~h}$ i.v., associated or not with an aminoglycoside (usually gentamicin or tobramycin $1.0 \mathrm{mg} . \mathrm{kg}^{-1} \mathrm{q} 8 \mathrm{~h}$ i.v. ${ }^{[5]}$.

Infections due to a methicillin-resistant strain should be treated with vancomycin $1 \mathrm{~g} \mathrm{q} 12$ h i.v. for 4 weeks, associated with or without rifampin $600 \mathrm{mg}^{\text {day }}{ }^{-1}$ orally for 4 weeks $^{[6]}$.

\section{Coagulase-negative staphylococci endocarditis}

Treatment regimens for staphylococcal endocarditis due to a coagulase-negative strain do not differ from those for $S$. aureus, as long as the strain is susceptible to the classical agents. No prospective study has yet been conducted with this rather unusual organism in the setting of native valve endocarditis, but a retrospective analysis of 35 cases suggests a better efficacy of combination therapy ${ }^{[7]}$.

\section{PROSTHETIC VALVE (TABLE 2)}

\section{Staphylococcus aureus infection}

This very serious form of $S$ aureus endocarditis is usually treated with an aminoglycoside (for 2 weeks), combined either to a PRP (such as oxacillin) if the strain is susceptible to PRPs, or to vancomycin, if the strain is resistant to PRPs. Some experts advocate the addition of rifampin.

\section{Coagulase-negative staphylococci infection}

The treatment of this rather frequent condition relies mostly on the susceptibility pattern of the causative organism. Early infections (defined as those occurring less than 1 year after surgery) tend to be due to multiresistant organisms acquired during the hospital stay, whereas late infections are more often caused by more susceptible community-acquired organisms. In the former situation, vancomycin is often combined with both gentamicin and rifampin, a regimen more effective than vancomycin alone $^{[8]}$.

Two antibiotics (vancomycin + rifampin for 6 weeks in methicillin-resistant cases) or three (with the addition of gentamicin for 2 weeks) were not found to be different in terms of cure rates, but the addition of the aminoglycoside prevented the emergence of resistance to rifampin ${ }^{[9]}$.

\section{SPECIAL SITUATIONS}

Allergy to $\beta$-lactam agents

In cases of severe reaction (immediate-type hypersensitivity), patients should be treated with vancomycin. In less severe cases, a cephalosporin (such as cephalothin or cefazolin) could be considered if the strain is not resistant to methicillin. However, not all cephalosporins are equivalent to PRP and not all are suitable for treating severe staphylococcal infections.

Because vancomycin could well be less efficacious than PRPs ${ }^{[6,10]}$, a history of allergy to $\beta$-lactams should be carefully documented before renouncing a $\beta$-lactam agent.

\section{Short regimens}

Right-sided $S$ aureus endocarditis in the IVDA could be cured by a shorter antibiotic regimen than that usually prescribed for the other presentations of staphylococcal endocarditis. This is important in view of the low compliance reported in this population. As already mentioned, 2 weeks of i.v. nafcillin $1.5 \mathrm{~g} \mathrm{q} 4 \mathrm{~h}$ associated with tobramycin $1 \mathrm{mg} \cdot \mathrm{kg}^{-1} \mathrm{q} 8 \mathrm{~h}$ gave a cure rate of $94 \%[5]$.

Another short i.v. regimen combines ciprofloxacin $300 \mathrm{mg} \mathrm{q} 12 \mathrm{~h}$ i.v. for 1 week followed by $750 \mathrm{mg} \mathrm{q} 12 \mathrm{~h}$ orally for three further weeks, with rifampin $300 \mathrm{mg} \mathrm{q} 12 \mathrm{~h}$ orally. This was successfully given to ten patients with rightsided $S$. aureus endocarditis ${ }^{[11]}$. Ciprofloxacin and related quinolones, however, are increasingly reported as being inactive on staphylococci.

\section{Alternative treatments to vancomycin}

Because vancomycin could not be the optimal treatment (slow killing, toxicity, delayed efficacy, fear for future resistant organisms), alternative regimens have been and should be considered. Trimethoprim-sulphamethoxazole could be effective for right-sided endocarditis ${ }^{[12]}$. Teicoplanin, an antibiotic related to vancomycin, could also be used if a high dose (12-24 mg.kg.day $\left.{ }^{-1}\right)$ therapy proves equivalent to, or better than, vancomycin.

\section{Future modalities}

Outpatient treatment for uncomplicated cases of endocarditis, either for the entire course of antibiotherapy or after medical stabilization, has been proved a success especially for penicillin-susceptible streptococci. For staphylococci, in low-risk patients without complications (heart failure, peripheral emboli) discharge to home after medical stabilization could well be considered, in particular, for patients requiring long-term therapy.

\section{NEW DRUG REGIMENS}

The association of $\beta$-lactamase inhibitors with various $\beta$ lactam agents (especially penicillins), has been shown to be active in vitro not only against methicillin-susceptible $S$ aureus strains $\left(\mathrm{MIC}_{90}: 1 \mu \mathrm{g} \cdot \mathrm{ml}^{-1}\right.$ ), but also to a lesser

Table 2 Antibiotic regimens for staphylococcal prosthetic valve endocarditis

\begin{tabular}{|c|c|c|c|}
\hline Staphylococcus aureus & \multicolumn{3}{|c|}{ As for native valve } \\
\hline \multicolumn{4}{|l|}{$\begin{array}{l}\text { Coagulase negative } \\
\text { staphylococci }\end{array}$} \\
\hline Methicillin-susceptible & \multicolumn{3}{|c|}{ As for native valve } \\
\hline Methicillin-resistant & $\begin{array}{l}\text { Vancomycin } \\
+ \text { rifampin } \\
+ \text { gentamicin }\end{array}$ & $\begin{array}{l}1 \mathrm{~g} \mathrm{q} 12 \mathrm{~h} \text { i.v. } \\
600 \mathrm{mg} \cdot \text { day orally } \\
1-0 \mathrm{mg} \cdot \mathrm{kg}^{-1} \mathrm{q} 8 \mathrm{~h} \text { i.v. }\end{array}$ & $\begin{array}{l}\times 6 \text { weeks } \\
\times 6 \text { weeks } \\
\times 2 \text { weeks }\end{array}$ \\
\hline
\end{tabular}


degree against methicillin-resistant strains (MIC90: $8-16 \mu \mathrm{g} \cdot \mathrm{ml}^{-1[13]}$. Several groups have demonstrated an in vivo efficacy of this combination in experimental endocarditis equal to or greater than that of vancomycin ${ }^{[3-16]}$.

In particular, $\beta$-lactamase-negative methicillin-resistant $S$ aureus strains are highly sensitive to $\beta$-lactam agents such as penicillin or amoxicillin, due to their affinity being higher than that of oxacillin for the penicillin-binding protein PBP 2a. We do not claim, at the present time, that the available associations should be used to treat severe infections and endocarditis due to methicillin-resistant $S$ aureus strains, but rather that $\beta$-lactam agents with a high affinity for PBP 2a should be looked at, in order to replace the classic treatment regimen when strains of staphylococci resistant to vancomycin eventually occur.

\section{References}

[1] Karchmer AW. Staphylococcal endocarditıs. In: Kaye D. ed. Infective Endocarditis, 2nd edn. New York: Raven Press, 1992: 225-49.

[2] Bisno AL, Dismukes WE, Durack DT et al. Antimicrobial treatment of infective endocarditis due to viridans streptococci, enterococci, and staphylococci. J Am Med Assoc 1989; 261: 1471-7.

[3] Korzeniowski O, Sande MA, the National Collaborative Endocarditis Study Group. Combination antimicrobial therapy for Staphylococcus aureus endocarditis in patients addicted to parenteral drugs and in nonaddicts: a prospective study. Ann Intern Med 1982: 97: 496-503.

[4] Kobasa WD, Kaye KL, Shapiro T, Kaye D. Therapy for experimental endocarditis due to Staphylococcus epidermidis. Rev Infect Dis 1983; 5 (Suppl 3): S533-7.

[5] Chambers HF, Miller T, Newman MD. Right-sided Staphylococcus aureus endocarditis in intravenous drug abusers: two-week combination therapy. Ann Intern Med $1988 ; 109: 619-24$.

[6] Levine DP, Fromm BS, Reddy BR. Slow response to vancomycin or vancomycin plus rifampin in methicillin-resistant Staphylococcus aureus endocarditis. Ann Intern Med 1991; 115: $674-80$.
[7] Etienne J, Eykyn SJ. Increase in native valve endocarditis caused by coagulase-negative staphylococci: an AngloFrench clinical and microbiological study. Br Heart J 1990; 64: 381-4.

[8] Karchmer AW, Archer GL, Dismukes WE. Staphylococcus epidermidis causing prosthetic valve endocarditis: microbiologic and clinical observations as guides to therapy. Ann Intern Med 1983; 98: 447-55.

[9] Karchmer AW, Archer GL, the National Collaborative Endocarditis Study Group. Methicillin-resistant Staphylococcus epidermidis prosthetic valve endocarditis: a therapeutic trial (Abstr 476). Presented at the 24th Interscience Conference on Antimicrobial Agents and Chemotherapy, American Society for Microbiology, Washington, October 1984.

[10] Small PM, Chambers HF, Vancomycin for Staphylococcus aureus endocarditis in intravenous drug users. Antimicrob Agents Chemother 1990; 34: 1227-31.

[11] Dworkin RJ, Lee BL, Sande MA, Chambers HF. Treatment of right-sided Staphylococcus aureus endocarditis in intravenous drug users with ciprofloxacin and rifampicin. Lancet 1989; 2: 1071-73.

[12] Markowitz N, Saravolatz L, Pohlod D et al. Comparative efficacy and toxicity of trimethoprim-sulfamethoxazole versus vancomycin in the therapy of serious $S$. aureus infections (Abstr 638). Presented at the 23rd Interscience Conference on Antimicrobial Agents and Chemotherapy, American Society for Microbiology, Las Vegas, October 1983.

[13] Cantoni L, Wenger A, Glauser MP, Bille J. Comparative efficacy of amoxicillin-clavulanate, cloxacillin, and vancomycin against methicillin-sensitive and methicillin-resistant Staphylococcus aureus endocarditis in rats. J Infect Dis 1989; 159: 989-93.

[14] Washburn RG, Durack DT. Efficacy of ampicillin plus a $\beta$ lactamase inhibitor (CP-45, 899) in experimental endocarditis due to Staphylococcus aureus. J Infect Dis 1981; 144: $237-43$.

[15] Hirano L, Bayer AS. $\beta$-Lactam- $\beta$-lactamase inhibitor combinations are active in experimental endocarditis caused by $\beta$-lactamase producing oxacillin-resistant staphylococci. Antimicrob Agents Chemother 1991; 35: 685-90.

[16] Franciolli M, Bille J, Glauser MP, Moreillon PH. $\beta$-Lactam resistance mechanisms of methicillin-resistant Staphylococcus aureus. J Infect Dis 1991; 163: 514-23. 